\title{
Tau Accumulation in Clinically Normal Older Adults Is Associated with Hippocampal Hyperactivity
}

\author{
CWillem Huijbers, ${ }^{1,2,3}$ Aaron P. Schultz, ${ }^{1,2}$ Kathryn V. Papp, ${ }^{1}$ Molly R. LaPoint, ${ }^{1,5}{ }^{\circ}$ Bernard Hanseeuw, ${ }^{1,6}$ \\ - Jasmeer P. Chhatwal, ${ }^{1,4}$ Trey Hedden, ${ }^{1,2}$-Keith A. Johnson, ${ }^{1,4}$ and ${ }^{\odot R e i s a ~ A . ~ S p e r l i n g ~}{ }^{1,2,4}$ \\ ${ }^{1}$ Harvard Aging Brain Study, Department of Neurology, Massachusetts General Hospital, Harvard Medical School, Boston, Massachusetts 02114, ${ }^{2}$ Athinoula \\ A. Martinos Center for Biomedical Imaging, Department of Radiology, Massachusetts General Hospital, Charlestown, Massachusetts 02129, ${ }^{3} \mathrm{Jheronimus}$ \\ Academy of Data Science, Department of Cognitive Science and Artificial Intelligence, Tilburg University, $5037 \mathrm{AB}$, Tilburg, the Netherlands, ${ }^{4} \mathrm{Center}$ for \\ Alzheimer Research and Treatment, Department of Neurology, Brigham and Women's Hospital, Harvard Medical School, Boston, Massachusetts 02115, \\ ${ }^{5}$ Helen Wills Neuroscience Institute, University of California Berkeley, Berkeley, California 94720, and 6Neurology Department, Saint-Luc University \\ Hospital, 1200 Brussels, Belgium
}

Animal studies demonstrate that hyperactive neurons facilitate early accumulation and spread of tau and amyloid- $\beta$ proteins in the pathological cascade of Alzheimer's disease (AD). Human neuroimaging studies have linked hippocampal hyperactivity to amyloid- $\beta$ accumulation, apolipoprotein $\varepsilon 4(\mathrm{APOE} 4)$ and clinical progression from prodromal AD to clinical dementia. The relationship between hippocampal hyperactivity and early AD molecular pathology (amyloid- $\beta$ and tau accumulation) before clinical symptoms remains to be elucidated. Here, we studied 120 clinically normal older humans ( 80 females/40 males) enrolled in the Harvard Aging Brain Study. We measured functional magnetic resonance imaging (fMRI) activity during successful memory encoding and amyloid- $\beta$ accumulation with PiB-positron emission tomography imaging. Additionally, we measured tau accumulation using AV1451 PET imaging in a subset of 87 participants. In this subset, we found that inferior temporal tau accumulation was associated with increased fMRI activity in the hippocampus, but showed no clear association with amyloid. Together, the findings support a hypothetical model of the evolution of preclinical AD that place hippocampal hyperactivity concurrent with spread of tau pathology to neocortical regions before clinical impairment.

Key words: Alzheimer's disease; excitotoxicity; flortaucipir; fMRI; memory; PiB

\section{Significance Statement}

The circumstances under which the hippocampus becomes hyperactive in preclinical stages of Alzheimer's disease (AD) have thus far remained elusive. Recent advances in positron emission tomography (PET) tracers now enable in vivo characterization of amyloid- $\beta$ and tau accumulation. Here, we combine amyloid and tau PET with functional magnetic resonance imaging (fMRI) to examine the association between Alzheimer's disease pathology and memory-related brain activity in clinically normal older adults. We found an association between increased hippocampal activity and tau accumulation in the inferior temporal cortex. These data suggest that the pathogenesis of hippocampal hyperactivity occurs concurrent with the spread of tau pathology from the entorhinal cortex to the neocortex, before the clinical manifestations of Alzheimer's disease.

\section{Introduction}

Neuronal hyperactivity has been implicated in the pathological cascade of Alzheimer's disease (AD; Palop et al., 2007; Bero et al.,
2011; Busche and Konnerth, 2015; Krüger and Mandelkow, 2016; Palop and Mucke, 2016; Haberman et al., 2017b). In animal models, hyperactivity is tightly linked to dysfunction of the hippocampus (Busche et al., 2008; Cacucci et al., 2008). In these models, hyperactive neurons can be found in hippocampus, be- 
fore emergence of memory deficits and hyperactivity is associated with amyloid- $\beta$ and tau protein accumulation (Abramowski et al., 2008; Palop and Mucke, 2010; DeVos et al., 2013; Krüger and Mandelkow, 2016; Wu et al., 2016).

Using functional magnetic resonance imaging (fMRI), several neuroimaging studies have reported hippocampal hyperactivity in patients with mild cognitive impairment (Johnson et al., 2004; Hämäläinen et al., 2007; Kircher et al., 2007; Huijbers et al., 2015). Hippocampal hyperactivity is also observed in asymptomatic individuals at genetic risk for developing $\mathrm{AD}$, including mutation carriers who will develop familial AD (Quiroz et al., 2010; 2015; Reiman et al., 2012) and in carriers of the apolipoprotein $\varepsilon 4$ (APOE4) at increased risk for sporadic AD (Bookheimer et al., 2000; Johnson et al., 2006; Tran et al., 2017). In humans, these increases in hippocampal fMRI activity might reflect a pathological response, or compensation, or both at the same time. Nevertheless, the pathogenesis and temporal course of hippocampal hyperactivity during the evolution of preclinical $\mathrm{AD}$ in older individuals remains to be elucidated.

The development of positron emission tomography (PET) agents for amyloid- $\beta$ and tau (Klunk et al., 2004; Xia et al., 2013) enables in vivo assessment of these pathologies and their relationships to fMRI activity during memory formation. Previous studies in preclinical $\mathrm{AD}$ have yielded variable reports on the relation between amyloid- $\beta$ PET and hippocampal fMRI activity (Kennedy et al., 2012; Mormino et al., 2012; Oh and Jagust, 2013; Vannini et al., 2013; Elman et al., 2014; Huijbers et al., 2014; Sperling et al., 2014a; Rieck et al., 2015; Lockhart et al., 2017; Marks et al., 2017). One potential reason for the discrepancies between studies may be that hippocampal hyperactivity begins later in the course of preclinical AD after amyloid- $\beta$ has started to accumulate, and might be more closely related to the spread of tau pathology (Sperling et al., 2014a). Recent advances in Tau PET imaging now allow this hypothesis to be tested. Initial crosssectional findings using AV1451 are consistent with autopsy studies (Johnson et al., 2016; Schöll et al., 2016), and suggest that tau accumulation begins in the medial temporal lobe before spreading into neocortical regions in the setting of amyloid- $\beta$ accumulation consistent with Braak staging (Braak and Braak, 1991). One recent study reported a link between increased hippocampal hyperactivity and tau accumulation (Marks et al., 2017). This study compared young with older adults, and found increased hippocampal activity in the older adults with tau accumulation in the hippocampus (Braak I/II). Moreover, previous work has suggested that APOE4 is particularly associated with hyperactivity (Bookheimer et al., 2000; Johnson et al., 2006; Filippini et al., 2011; Tran et al., 2017). Here, we examine the relation between tau in inferior temporal and entorhinal cortex within a large sample of older adults. This allows us to clarify whether tau accumulation in these regions is associated with hippocampal activity and APOE4. Our motivation to examine tau in inferior temporal and entorhinal cortex is driven by associations with cognitive decline across the AD spectrum with amyloid deposition in cognitive normal older adults (Johnson et al., 2016). Using amyloid in the neocortex, tau PET, and APOE4 status, we

RR023043. The content is solely the responsibility of the authors and does not necessarily represent the official views of the National Institute on Aging or the National Institutes of Health. Information on the Harvard Aging Brain Study can be found at: http://www.nmr.mgh.harvard.edu/harvardagingbrain.

The authors declare no competing financial interests.

Correspondence should be addressed to Dr. Willem Huijbers, Department of Cognitive Science and Artificial Intelligence, Tilburg University, The Netherlands 5032 CH. E-mail: w.huijbers@uvt.nl.

https://doi.org/10.1523/JNEUROSCI.1397-18.2018

Copyright $\odot 2019$ the authors $\quad 0270-6474 / 19 / 390549-09 \$ 15.00 / 0$ can further refine our understanding of hippocampal hyperactivity in older adults (Sperling et al., 2014a; Villemagne and Chételat, 2016) and examine the preclinical associations between these markers and hippocampal fMRI activity in clinically normal older adults.

\section{Materials and Methods}

One hundred and twenty normal older adults (aged 63-90, $\mathrm{M}=75.22$, $\mathrm{SD}=6.6$, female $=80$ ) were recruited from the Harvard Aging Brain Study, an ongoing study designed to further our understanding of normal aging and preclinical Alzheimer's disease (Dagley et al., 2017). All participants were fluent English speakers and had normal or correctedto-normal vision. Participants were cognitively normal based on the Mini Mental State Exam (score > 26; RRID:SCR_003681; Folstein et al., 1975) and scored above age- and education-adjusted cutoffs on the 30 min Delayed Recall of the Logical Memory Story IIa (score $>11$; Wechsler, 1984). Ten of the 120 participants were rated 0.5 on the global Clinical Dementia Rating (CDR; RRID:SCR_003678; Morris, 1993) within 1 year of their PET imaging, however, none met criteria for mild cognitive impairment (MCI; Petersen, 2004). Written informed consent was obtained from every participant before experimental procedures and the study was approved and conducted in accordance with the Partners Human Research Committee at the Massachusetts General Hospital and Brigham and Women's Hospital.

In all 120 older adults, we measured functional MRI during memory encoding of novel faces. We also obtained a structural MRI using a T1MPRAGE, and a PET scan, using Pittsburg Compound B, to measure amyloid- $\beta$ accumulation and a comprehensive neuropsychological examination. In a subcohort of 87 participants, we also obtained a PET scan using 18-F-AV-1451, also known as "T807" or "Flortaucapir", to measure tau accumulation. In one control analysis, we further examine a subcohort of 80 adults, who have been characterized by APOE4 status and all of the above-mentioned imaging markers: (f)MRI, amyloid and tau PET (see Table 2). The average time differences (in days) between the visit for MRI, amyloid PET [Pittsburgh Compound B (PiB)], tau PET (AV1451), and the neuropsychological (NP) examination was $143 \mathrm{~d} \pm$ 239 for MRIvsPiB $(\min =4 ; \max =1088) ; 137 \mathrm{~d} \pm 99$ for MRIvsAV1451 $(\min =7 ; \max =1211) ; 182 \mathrm{~d} \pm 252$ for PiBvsAV1451 $(\min =2 ; \max =$ $1149) ; 67 \mathrm{~d} \pm 61$ for MRIvsNP $(\min =0 ; \max =214) ; 196 \mathrm{~d} \pm 221$ for PiBvsNP $(\min =0 ; \max =1048)$ and $156 \mathrm{~d} \pm 99$ for AV1451vsNP $(\min =16 ; \max =356)$.

Memory encoding task. The memory-encoding task was comprised of 48 novel faces shown for 7500 milliseconds each during the MRI scan. The face stimuli were color photos of unfamiliar individuals who varied in age (range 18-90 years), ethnicity, and sex. The novel faces were intermingled with 120 famous faces and participants indicated whether they knew the face or not. Because we focused on novel memory encoding, which robustly engages the hippocampus, data from these famous faces is not included in the current paper (Huijbers et al., 2017). In the intertrial interval, participants viewed a white fixation cross for a duration between 500 and 12,500 ms. The trial order and durations of the intertrial intervals were optimized using optseq2 (Dale, 1999). Visual stimuli were projected on a screen positioned at the head of the magnet bore and seen via a mirror attached to the head coil. Responses were made with the right hand using an MRI-compatible button-box. Head motion was restrained with foam pads and scanner noise was minimized using earplugs and noise-reduction headphones. Following the MRI participants conducted a recognition test of the 48 faces encoded during the MRI scan intermingled with another 48 novel faces (foils). Participants indicated via a response-box whether they had previously seen each face or not. The post-scan recognition test was self-paced.

Magnetic resonance imaging. The MRI data were collected on two matched Siemens TrioTim 3.0 tesla scanners at the Athinoula A. Martinos Center for Biomedical Imaging (RRID:SCR_012324). Both scanners were equipped with a 12-channel phased-array head coil. Highresolution T1-weighted anatomical images were acquired using an MPRAGE with the following parameters: 256 sagittal slices, repetition time $(\mathrm{TR})=2300 \mathrm{~ms}$, echo time $(\mathrm{TE})=2.95 \mathrm{~ms}$, inversion time $=900$ 
A

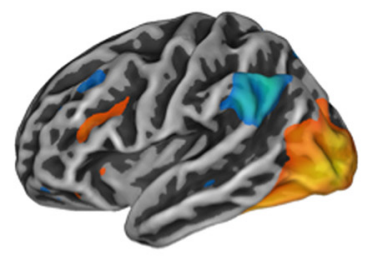

Positive ESA (Hits > Misses) 0

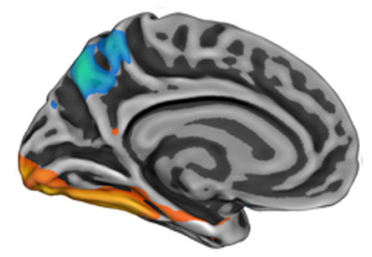

9.8

\section{Encoding Success Activity (fMRI)}

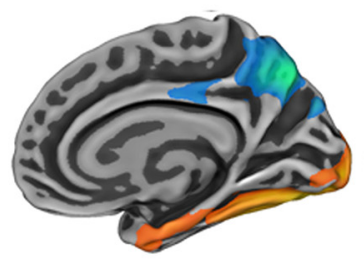

Negative ESA

(Misses $>$ Hits) 0

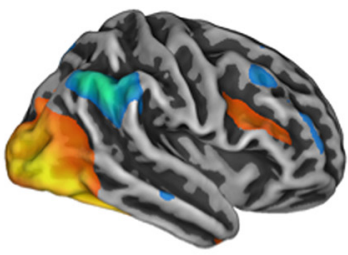

(fdr) 3.6
7.3

B
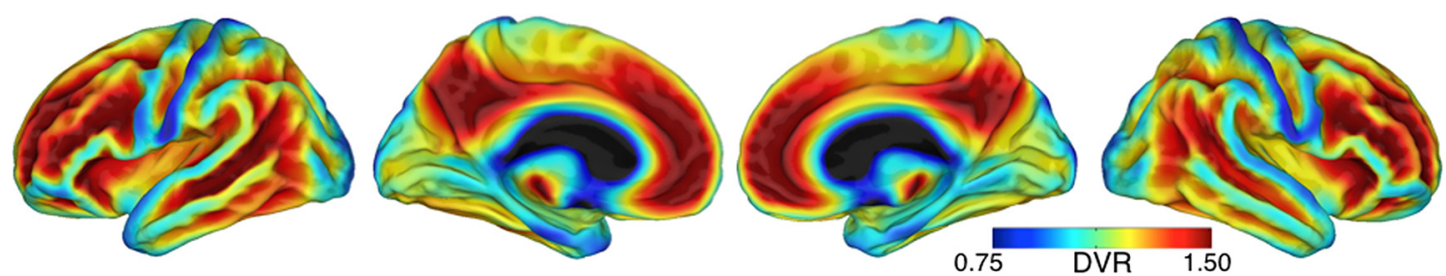

C Tau Accumulation (AV1451)
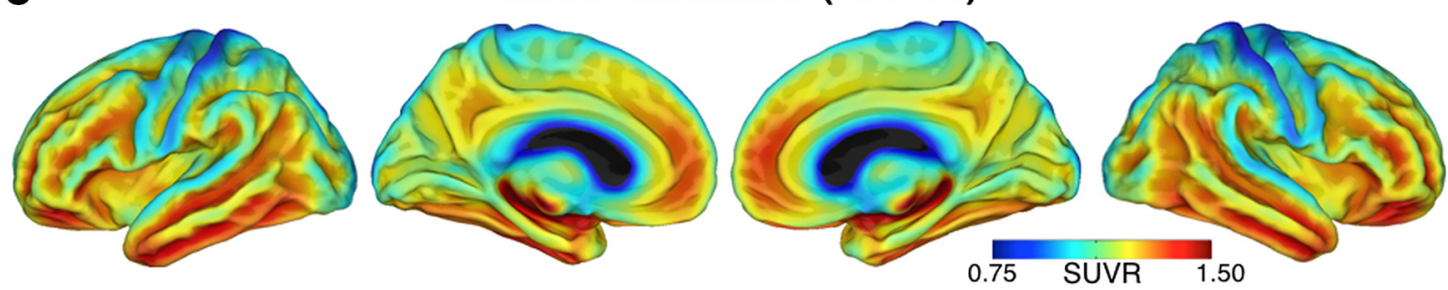

Figure 1. Whole-brain maps illustrating the colocalization of fMRI activity, amyloid- $\beta$, and tau accumulation. $A$, Task-evoked fMRI activity across all participants on the cortical surface ( $p<0.05$, FDR-corrected). Warm colors show positive encoding success activity, cool colors show negative encoding success activity. $\boldsymbol{B}$, The mean amyloid- $\beta$ accumulation using PET-PiB expressed as DVR across all participants. The red colors indicate areas with high levels of accumulation and blue with low. $C$, The mean tau accumulation, using PET-AV1451 expressed and SUVR across the subset with tau data.

$\mathrm{ms}$, flip angle $(\mathrm{FA})=9^{\circ}$, field of view $(\mathrm{FOV})=270 \times 253 \mathrm{~mm}$, matrix $=$ $256 \times 240$, voxel size $=1.05 \times 1.05 \times 1.2 \mathrm{~mm}$. Task-evoked fMRI using blood oxygenation level-dependent (BOLD) contrast were acquired using a T2*-weighted gradient-echoplanar (EPI) sequence. We acquired 6 fMRI time series of 180 volumes (after excluding 4 dummies). Each volume consisted of 33 axial slices, $3.0 \mathrm{~mm}$ thickness, with a skip of 0.8 $\mathrm{mm} ; \mathrm{TR}=2000 \mathrm{~ms} ; \mathrm{TE}=30 \mathrm{~ms} ; \mathrm{FA}=90^{\circ}, \mathrm{FOV}=192 \times 192 \mathrm{~mm}$, matrix $=64 \times 64$, effective voxel size $=3.0 \times 3.0 \times 3.8 \mathrm{~mm}$.

The fMRI time series were preprocessed and analyzed using SPM8 (RRID:SCR_007037). The data were slice time-corrected, realigned and normalized to the MNI EPI template, resampled to $3.0 \times 3.0 \times 3.0 \mathrm{~mm}$ voxels and smoothed with $8 \mathrm{~mm}$ full-width half-maximum Gaussian kernel general linear model (GLM)-Flex was used to perform group level voxelwise whole-brain analyses (Harvard Aging Brain Study, Martinos Center, MGH, ). The event-types in the GLM were defined by the experimental design and coded as novel or famous. The novel items were separately included in the SPM model based on the responses from the subsequent memory test (encoding hit or encoding miss). The famous items were also modeled, but these data are not reported here. Similarly, omissions were included in the SPM model, but not used in any of the analyses. Group fMRI analyses consisted of voxelwise one-sample $t$ tests using the contrasts: encoding hit $>$ encoding miss (positive encoding success activity) or encoding miss $>$ encoding hit (negative encoding success activity). We used a threshold of $p<0.05$, FDR-corrected with a minimum cluster size of 20 voxels $\left(540 \mathrm{~mm}^{3}\right.$; Fig. 1A). Statistical group maps were visualized using FIVE (Harvard Aging Brain Study, Martinos Center, MGH, ) and either projected to the cortical surface via a standard MNI to the FreeSurfer fsaverage transformation (Fig. $1 A$ ) or overlaid on the standard SPM8 T1-weighted volume (Fig. 2A). In addition, we extracted the $\beta$ estimates using a $5 \mathrm{~mm}$ radius at peaks of activity from the left hippocampus and $\left(\mathrm{MNI}_{(x, y, z)}=-24,-10,-22\right)$ and right hippocampus $\left(\mathrm{MNI}_{(x, y, z)}=27,-4,-28\right)$, defined by the contrast for posi- tive encoding success activity (encoding hit $>$ encoding miss). We used the individual $\beta$-estimates to calculate the mean activity for use in linear models.

Positron emission tomography. The PET data were collected on Siemens ECAT HR+ scanner at Massachusetts General Hospital (RRID: SCR_012544). The PET data were collected in 3D mode; 63 image planes; $152 \mathrm{~mm}$ axial FOV; $5.6 \mathrm{~mm}$ transaxial resolution and $2.4 \mathrm{~mm}$ slice interval. The data were reconstructed, attenuation corrected, and evaluated to verify adequate count statistics and absence of head motion. PET images were coregistered to the corresponding T1-MPRAGE image for each subject using a 6 degree of freedom, rigid body registration, and structural ROIs, as determined by FreeSurfer (RRID:SCR_001847), were mapped into native PET space. The ROIs were delineated with individual anatomy, using the standard FreeSurfer Desikan-Killiany parcellation, as assembled into the GTM volumetric segmentation by the FS PET routines (gtmseg) introduced by Greve et al. (2016). PiB (N-methyl- $\left[{ }^{11} \mathrm{C}\right]-$ 2(4-methylaminophenyl)-6-hydroxybenzothiazole) was prepared and acquired using previously described methods (Mathis et al., 2002; Johnson et al., 2007). Briefly, PiB (10-15 mCi) was injected as a bolus, followed by 60 min of dynamic PET acquisition in 69 frames ( 12 frames of 15 s; 57 frames of 60 s). AV1451 (T807: $\left[{ }^{18} \mathrm{~F}\right]$ 7-(6-nitropyridin-3-yl)-5Hpyrido[4,3-b]indole; Avid Radiopharmaceuticals) was prepared and acquired using previously described methods (Johnson et al., 2016). Briefly, AV1451 images were acquired from $80-100 \mathrm{~min}$ in $4 \times 5 \mathrm{~min}$ frames after a $10.0 \pm 1.0 \mathrm{mCi}$ bolus injection. For both PiB and AV1451, we used a cerebellar gray matter reference region from the FreeSurfer aseg atlas as previously described (Becker et al., 2011). AV1451 measures were computed as standardized uptake value ratios (SUVR), and PiB measures were computed as distribution volume ratios (DVRs) using the Logan graphical method (Logan et al., 1990) with slopes calculated over the 40-60 min time frame. Additionally we performed partial volume correction using the geometric transform matrix 

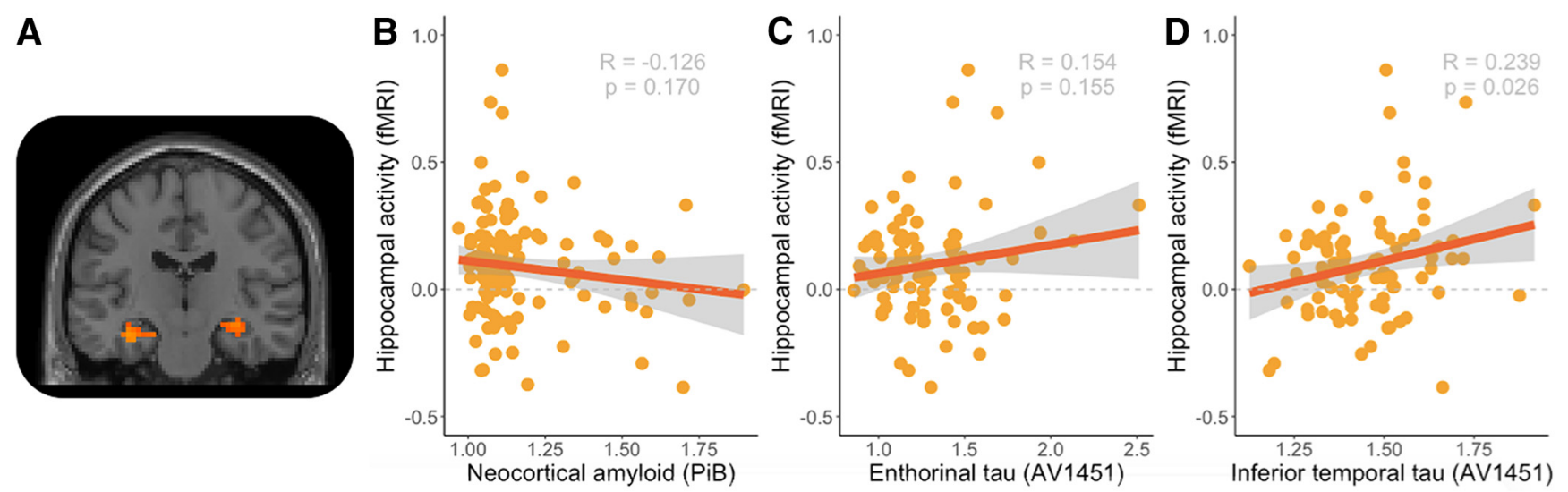

Figure 2. Scatterplots of associations with hippocampal activity. $\boldsymbol{A}$, The T1-weighted slice illustrates fMRI activity in the hippocampus ( $p<0.05$, FDR-corrected). $\boldsymbol{B}$, Scatterplot of hippocampal activity and neocortical amyloid- $\beta$ (PiB). C, Scatterplot of hippocampal activity and entorhinal tau (AV1451). D, Scatterplot of hippocampal activity and inferior temporal tau. The line indicates the best fit for a linear regression model. $R$ denotes the correlation coefficient, $N=$ the number of observations. $p=p$-value.

Table 1. Participants information in subset of the Harvard Aging Brain Study

\begin{tabular}{|c|c|c|c|c|c|}
\hline & All participants & Tau and amyloid & Amyloid only & Stats & $p$ \\
\hline$N$ & 120 & 87 & 33 & & \\
\hline Age & $75.22 \pm 6.60$ & $75.00 \pm 6.74$ & $75.38 \pm 6.15$ & $\mathrm{~T}=0.16$ & 0.87 \\
\hline Gender & 80 이요 & $52+/ 28$ o & $23 q / 10$ ठ & $\chi^{2}=0.05$ & 0.83 \\
\hline Education, $y$ & $16.30 \pm 3.07$ & $16.41 \pm 3.14$ & $16.27 \pm 2.49$ & $T=0.06$ & 0.95 \\
\hline CDR & 109 CDRO/11 CDR. 5 & 70 CDRO/10 CDR.5 & 70 CDR0/1 CDR. 5 & $\chi^{2}=1.20$ & 0.27 \\
\hline CDR, sum of boxes (SB) & $0.14 \pm 0.32$ & $0.17 \pm 0.36$ & $0.12 \pm 0.22$ & $T=0.46$ & 0.65 \\
\hline Recognition Accuracy, hit rate & $0.69 \pm 0.19$ & $0.69 \pm 0.19$ & $0.67 \pm 0.17$ & $\mathrm{~T}=0.53$ & 0.60 \\
\hline Recognition Errors, false-alarm rate & $0.11 \pm 0.12$ & $0.12 \pm 0.12$ & $0.11 \pm 0.11$ & $\mathrm{~T}=0.38$ & 0.70 \\
\hline$d^{\prime}$ & $1.96 \pm 0.78$ & $1.94 \pm 0.81$ & $1.93 \pm 0.72$ & $\mathrm{~T}=0.22$ & 0.82 \\
\hline APOE4 status $(\varepsilon 4)$ & $74 \varepsilon 4-/ 36 \varepsilon 4+$ & $52 \varepsilon 4-/ 28 \varepsilon 4+$ & $22 \varepsilon 4-/ 8 \varepsilon 4+$ & $\chi^{2}=0.36$ & 0.55 \\
\hline Amyloid status $(A \beta)$ & $93 A \beta-/ 27 A \beta+$ & $59 A \beta-/ 21 A \beta+$ & $29 A \beta-/ 4 A \beta+$ & $\chi^{2}=2.05$ & 0.15 \\
\hline Neocortical $A \beta$ (PiB) & $1.17 \pm 0.18$ & $1.17 \pm 0.18$ & $1.16 \pm 0.19$ & $T=0.37$ & 0.37 \\
\hline Entorhinal tau (AV1451) & $1.31 \pm 0.29$ & $1.31 \pm 0.29$ & NA & NA & \\
\hline Inferior temporal tau (AV1451) & $1.45 \pm 0.15$ & $1.46 \pm 0.14$ & NA & NA & \\
\hline
\end{tabular}

$N$ denotes the number of participants. + , Female; $\hat{\sigma}$, male; $d^{\prime}$, memory performance.

The left column shows the demographics from the entire and the right columns show the demographics from sub-cohort tau PET data.

method (Rousset et al., 1998) as implemented in FreeSurfer v6.0, and described by Greve et al. (2016)), using a slightly modified FreeSurfer atlas mapped to each subjects native PET space that included ROIs for CSF, white matter, and extra-cerebral structures. The partial volume correction processing was performed assuming a uniform $6 \mathrm{~mm}$ point spread function.

For the statistical analysis of the behavioral data, we used $t$ tests (two-sided) and Pearson correlations (denoted as $R$ ). Unless stated differently, $\mathrm{M}$ denotes the mean (SD), df, the degrees of freedom, and \pm SEM. In addition to the whole-brain analysis (Fig. 1), we quantified amyloid- $\beta(\mathrm{PiB})$ in the neocortex using a composite that included regions in the association cortex, comprised of frontal, lateral, and retrosplenial regions, as previously described (Sperling et al., 2009). Based on the findings by Johnson et al. (2016), we focused our region of interest analysis of AV1451 on the inferior temporal cortex and the entorhinal cortex. To assess relationships between PET-amyloid (PiB) or PET-tau (AV1451) and encoding success activity (fMRI), we used linear regression models implemented in R v3.0.1 (RRID: SCR_001905; ) and the companion to Applied Regression Toolbox (Fox and Weisberg, 2011). We used ggplot2 (RRID:SCR_014601) for data visualization.

\section{Results}

Group demographics and behavioral results

Demographic variables for the entire sample and subset with tau PET imaging are presented in Table 1 . We did not find statistically significant differences between the low- and high-PiB groups. The percentage of successfully encoded items (hit rate) was $68.5 \pm 1.7 \%$ and the percentage of incorrectly endorsed novel foils (false-alarm rate) was $11.4 \pm 1.1 \%$. Memory performance, as defined by D-prime, was $1.96 \pm 0.07$. During the MRI, the response times for hits were $2795 \pm 63 \mathrm{~ms}$ and for misses $3719 \pm 92 \mathrm{~ms}$. A paired $t$ test demonstrated that the hits were significantly faster than the misses $(t=10.89, \mathrm{df}=119, p<$ $0.001)$. During the subsequent memory test, the response times for hits were $1872 \pm 48 \mathrm{~ms}$, for misses $2215 \pm 81 \mathrm{~ms}$, for correct rejections $1837 \pm 56 \mathrm{~ms}$ and for false alarms $2601 \pm 147 \mathrm{~ms}$ Paired $t$ tests again demonstrated that hits were significantly faster than misses $(t=5.46, \mathrm{df}=119, p<0.001)$, and similarly correct rejections were judged faster than false alarms $(t=5.98$, df $=107, p<0.001)$.

\section{Whole-brain maps}

We first visualized whole-brain fMRI activity and identified brain regions functionally engaged during successful memory formation (Fig. $1 A ; p<0.05$ FDR-corrected). We found positive encoding success activity (hits $>$ misses) in the visual cortex, fusiform gyrus, parahippocampus and hippocampus, and negative encoding success activity (misses $>$ hits) in the posteromedial cortex, anterior cingulate cortex, angular gyrus and lateral temporal cortex, As also noted by previous studies, the regions that show negative encoding success activity resemble a subset of 
the default-mode network (Daselaar et al., 2004; Gilmore et al., 2015) and have been described as a "core memory network"(Rugg and Vilberg, 2013). The positive encoding success activity resembles a subset of task-positive regions (Fox et al., 2005) that overlap with the ventral stream (Goodale and Milner, 1992). Second, we visualized whole-brain amyloid- $\beta$ PET DVR using neocortical $\mathrm{PiB}$ uptake with the cerebellar gray matter as the reference region (Fig. 1B). To exemplify the anatomic pattern of amyloid accumulation in preclinical $\mathrm{AD}$, we created a contrast between the 30 cognitively normal older adults with the highest global cortical amyloid uptake compared with 30 adults with the lowest uptake, so as not to bias the maps by uptake in any specific region. What can be appreciated visually is that difference in amyloid- $\beta$ accumulation is most pronounced in the heteromodal association cortex, including the posteromedial cortex, anterior cingulate cortex, angular gyrus, and lateral temporal regions, a set of regions that include the above referenced default-mode network (Raichle et al., 2001; Buckner et al., 2005). Third, we visualized whole-brain tau PET SUVR using the ratio of local AV1451 uptake divided by uptake in cerebellar gray matter (Fig. 1C). To exemplify the anatomic pattern of tau accumulation in preclinical $\mathrm{AD}$, we again created contract between the 30 cognitively normal older adults with the highest global tau uptake compared with 30 adults with the lowest tau uptake. What can be appreciated visually is that difference in tau accumulation is most pronounced in in the temporal lobe. This pattern of tau accumulation in clinically normal older adults is consistent with recent tau PET studies across the spectrum of Alzheimer's disease (Johnson et al., 2016; Ossenkoppele et al., 2016; Schöll et al., 2016; Jack et al., 2018).

\section{Region-of-interest}

To assess the relationship between fMRI, amyloid- $\beta$ and tau PET, we used region-of-interest (ROI) analyses based on previous studies. For amyloid- $\beta$ PET (PiB), we used a composite ROI of association cortices (Mormino et al., 2014). For tau PET (AV1451), we examined ROIs in the entorhinal cortex and inferior temporal cortex (Johnson et al., 2016). In previous work from our group, the inferior temporal ROI has consistently shown the largest effect size in AV1451 between clinically normal adults and MCI/AD patients. In cognitively normal older adults, inferior temporal tau might be a putative marker of early $\mathrm{AD}$-related tau spread into the neocortex, whereas entorhinal tau is observed nearly ubiquitously in advanced aging (Johnson et al., 2016). Thus, comparing the relation between hippocampal fMRI activity and entorhinal versus inferior temporal tau provides a cross-sectional hint regarding the relative stage of tau spreading at which the hippocampus may become hyperactive. In the subset of 87 older adults with tau PET imaging, we found that regional tau levels in the inferior temporal and entorhinal cortex were correlated $(r=0.589, t=$ $6.73, \mathrm{df}=85, p<0.001)$. PiB amyloid level in the neocortex was correlated with both inferior temporal AV1451 $(r=0.340, t=$ $3.33, \mathrm{df}=85, p=0.001)$ and entorhinal AV1451 $(r=0.364, t=$ $3.60, \mathrm{df}=85, p<0.001$ ), such that greater amyloid accumulation was associated with greater neocortical and entorhinal tau accumulation.

Figure $2 A$ shows no relation between positive encoding success activity in the hippocampus and amyloid- $\beta$ accumulation in the cortex $(r=-0.126, t=-1.38, \mathrm{df}=118, p=0.170)$. Figure $2 B$ shows no relation between positive encoding success activity in the hippocampus and tau accumulation in the entorhinal cortex $(r=0.155, t=1.433, \mathrm{df}=85, p=0.332)$. However, we observed a positive relationship between positive encoding success activity in the hippocampus and tau accumulation in the
Table 2. Predictors of hippocampal hyperactivity

\begin{tabular}{lcccc}
\hline & \multicolumn{4}{l}{ Dependent variable: hippocampal hyperactivity, fMRI } \\
\cline { 2 - 5 } & Model I & Model II & Model III & Model IV \\
\hline Amyloid (PiB) & -0.175 & & $-0.327^{* * *}$ & $-0.445^{* * *}$ \\
Tau (AV1451) & & $0.302^{*}$ & $0.426^{* *}$ & $0.596^{* * *}$ \\
APOE4 & & & & $0.088^{*}$ \\
Age & 0.003 & 0.002 & 0.003 & 0.003 \\
Sex & -0.033 & -0.023 & -0.017 & -0.027 \\
Education & 0.004 & 0.004 & 0.005 & 0.005 \\
Constant & -0.004 & -0.534 & -0.413 & $-0.583^{*}$ \\
Observations & 120 & 87 & 87 & 80 \\
$R^{2}$ & 0.030 & 0.064 & 0.132 & 0.215 \\
Adjusted $R^{2}$ & -0.004 & 0.018 & 0.078 & 0.150 \\
\hline
\end{tabular}

Linear regression models: four models that examine predictors of hippocampal fMRI activity. Model I includes amyloid- $\beta$ (PiB) as a predictor, Model II includes inferior temporal tau (AV1451). Model III includes both amyloid- $\beta$ and tau. Model IV includes amyloid- $\beta$, tau and APOE4 status. Each model includes the control variables, age, sex, and years of education. ${ }^{*} p<0.1,{ }^{* *} p<0.05,{ }^{* * *} p<0.01$.

inferior temporal region (Fig. $2 C ; r=0.239, t=2.27, \mathrm{df}=85, p=$ $0.026)$. Thus, greater tau accumulation in inferior temporal is associated with increased activity in the hippocampus. Next, we used linear models to further clarify the relation between fMRI activity in the hippocampus and AV1451 signal (Table 2). The linear models confirm that tau accumulation is related to increased hippocampal activity, with and without controlling for amyloid- $\beta$ accumulation, APOE4 status, age, sex and education. In addition, we ran models including the interaction between amyloid- $\beta$ and tau, but this interaction term was not significant.

Finally, to aid in interpretation of our results, we examined the associations between the brain and behavioral measurements across participants. We correlated the main neuroimaging measurements; hippocampal fMRI activity, inferior temporal tau (AV1451), and neocortical amyloid (PiB), with the main behavioral measurements; D-prime, hit rate, false-alarm rate, and the response times (rt) for hits and correct rejections (CRs), while controlling for age, sex, and education. We only found a significant partial correlation between the false-alarm rate and interior temporal tau $(r=0.254 t=2.32, \mathrm{df}=85, p=0.020)$.

\section{Discussion}

In clinically normal older adults, we found that increased hippocampal fMRI activity was associated with greater tau accumulation in the inferior temporal neocortex, but not with amyloid- $\beta$ accumulation. However, tau related hippocampal hyperactivity is not easily explained by a single factor. When hippocampal activity is examined in a model with amyloid, tau and APOE4, there are also associations with amyloid accumulation and APOE4. These findings in cognitively normal older adults suggest that hippocampal hyperactivity begins in preclinical stages and may be an integral part of the destructive cycle of AD pathophysiology.

\section{Aberrant activity}

Aberrant brain activity in the hippocampus is a relatively consistent finding in animal models of AD and is associated with nearly all markers of $\mathrm{AD}$, including amyloid, tau, and neurodegeneration (Palop and Mucke, 2016; Haberman et al., 2017a). In humans, aberrant epileptiform brain activity, as measured via electroencephalography, may also play a role in $\mathrm{AD}$ progression (Rao et al., 2009; Vossel et al., 2013, 2016). A role for aberrant brain activity in the development of $\mathrm{AD}$ is also consistent with the higher prevalence for seizures in familial AD (Zarea et al., 2016). The most compelling evidence for hippocampal hyperactivity, as measured by fMRI, is observed in familial AD. Mutation carriers 
typically show increased hippocampal activity during memory encoding compared with non-carriers (Quiroz et al., 2010, 2015; Reiman et al., 2012). In sporadic AD, APOE4 carriers have been repeatedly associated with hippocampal hyperactivity, most notably in preclinical stages (Bookheimer et al., 2000; Johnson et al., 2006; Tran et al., 2017). These findings, together with our current results, add to the body of evidence that increased hippocampal activity is associated with $\mathrm{AD}$ pathology, most notably tau.

Our work replicates some of the main findings by Marks et al. (2017), but also provides new insight into hippocampal hyperactivity. We found a similar association between hippocampal hyperactivity and tau in an independent cohort nearly three times larger. Yet, our findings also differ in several respects. First, Marks et al. (2017) identified hyperactivity relative to young adults. Our cohort, the Harvard Aging Brain Study, includes only older adults. We identified hyperactivity, within older adults, relative to tau pathology and independent of task performance. Both studies also used different memory paradigms to evoke fMRI activity. Marks et al. (2017) used a pattern segregationcompletion paradigm (Yassa and Stark, 2011). Using this paradigm, Marks et al. (2017) found that "pathological activity" evoked by false alarms, correlated with tau accumulation. This finding is somewhat consistent with our behavioral correlation between tau and the number of false alarms in the post-scan recognition. Here, we used a face memory encoding paradigm to elicit fMRI activity. In addition to the association with tau, we also found a negative association with amyloid with the same contrast (hits vs miss). In the study by Marks et al. (2017), the association with amyloid was positive, but relative to another contrast, that identified deactivations (hits vs baseline). In sum, whereas Marks et al. (2017) found specific amyloid and specific tau effects on different task conditions, we find that amyloid and tau demonstrate opposing influences on same task-evoked measurement of hippocampal activity.

\section{Aberrant or compensatory activity?}

One interpretation is that increased fMRI activity can be compensatory (Kircher et al., 2007; Miller et al., 2008; Mormino et al., 2012; Elman et al., 2014). Elman et al. (2014) demonstrated that clinically normal older adults with amyloid- $\beta$ accumulation show compensatory activity in neocortical brain regions outside of the default-network, including so-called task-positive brain regions (Fox et al., 2005). These compensatory increases in activity are associated with better memory performance. Yet, no association with memory performance was found with hippocampal activity, consistent with our current findings. Several other studies have converged on a "cognitive reserve network" (Stern et al., 2005; Barulli and Stern, 2013; Franzmeier et al., 2017). This reserve network overlaps with task-positive brain regions most notably in the prefrontal cortex, and does not include the hippocampus or default-network. The idea of a cognitive reserve network implies that compensation is not only possible via local increases in brain activity, but via reorganization of activity in connected brain regions (Park and Reuter-Lorenz, 2009; Franzmeier et al., 2018). Thus, one possibility is that compensatory activity typically occurs in task-positive regions, whereas increased activity in the hippocampus and default-network are more likely to reflect aberrant processes. Cross-sectional studies cannot provide a definitive answer. It remains an open question if increased hippocampal activity, in relation to tau accumulation, is compensatory, a sign of impending pathological hippocampal failure or potentially evidence of both processes. Longitudinal and intervention studies are required to evaluate these competing hypotheses.

\section{Hyperactivity is associated with tau aggregation}

Our findings provide a potential explanation for discrepancies between existing fMRI studies of hippocampal hyperactivity and neocortical amyloid- $\beta$ accumulation in clinically normal older adults. Our results indicate that hippocampal hyperactivity is most clearly seen in the setting of elevated neocortical tau accumulation, consistent with other recent reports (Lockhart et al., 2017; Marks et al., 2017). Together these results suggest that varying degrees of tau accumulation in the inferior temporal cortex might help explain why some studies in clinically normal adults found hippocampal hyperactivity (Mormino et al., 2012; Oh and Jagust, 2013), whereas other studies did not (Kennedy et al., 2012; Vannini et al., 2013; Elman et al., 2014; Huijbers et al., 2014; Rieck et al., 2015; Foster et al., 2018). Histopathological studies indicate tau aggregation starts in the entorhinal cortex (Braak and Braak, 1991; Nelson et al., 2012) and is nearly ubiquitous in advanced aging, whereas tau in the inferior temporal cortex is indicative of more advanced stages of preclinical AD (Jack et al., 2016). We found that hippocampal hyperactivity was associated with tau in the inferior temporal cortex, but not with tau in the entorhinal cortex. These findings are also consistent with our previous work, before the advent of tau PET imaging, where we only observed hippocampal hyperactivity in a subset of older individuals with elevated amyloid and a CDR 0.5 , but not yet meeting MCI criteria (Sperling et al., 2009), as well as our previous studies in MCI patients with evidence of elevated amyloid-B (Huijbers et al., 2015). We suspect that these participants with early cognitive impairment would have been likely to have elevated neocortical tau as well. In sum, the results suggest that the hippocampus becomes hyperactive, relatively independent of amyloid, concurrent with the spread of tau from the entorhinal cortex to the neocortex, before cognitive impairment.

Our findings suggest that hippocampal hyperactivity is mostly driven by tau accumulation, although, we also find an influence of amyloid and APOE4. In cognitively normal older adults, tau and amyloid accumulation seem to have an opposite influence on hippocampal activity. This suggests that previous studies, which found a positive association between hippocampal activity and amyloid accumulation, might actually have been driven by tau accumulation (Mormino et al., 2009; Sperling et al., 2009). Note APOE4 is likely to interact with amyloid and tau accumulation. However, segregating the influence of amyloid, tau, and APOE4 is currently beyond the scope (and statistical power) of our cohort. APOE4 carriers tend to show increased hippocampal activity much earlier in life compared with non-carriers (Jagust, 2016). In APOE4 carriers, increased hippocampal activity has been shown in mid-twenties, before accumulation of amyloid and tau (Bookheimer et al., 2000; Dennis et al., 2010; Filippini et al., 2011). Hippocampal hyperactivity could therefore also precede, and facilitate, the accumulation of amyloid and tau in APOE4 carriers. Future longitudinal studies, that include APOE4 carriers and APOE4 non-carriers in mid-life might prove very helpful in answering the open question regarding whether hyperactivity facilitates the accumulation of amyloid and tau.

\section{Limitations}

A first limitation is the cross-sectional nature of the data. We cannot draw strong inferences about the order of events or the progression of $\mathrm{AD}$ pathology based on these data alone. Nevertheless, several recent studies have linked hippocampal hyperac- 
tivity to cognitive decline (Huijbers et al., 2015) and amyloid accumulation (Leal et al., 2017). Together with other studies that found an association between tau and cognitive decline (Johnson et al., 2016; Buckley et al., 2017), and hyperactivity (Lockhart et al., 2017; Marks et al., 2017) this suggest a role for hippocampal hyperactivity in disease progression. Yet, without interventions and longitudinal measure of cognition, fMRI, amyloid, and tau, it is impossible to elucidate the sequence of events. A second limitation is that in a subset of participants $(n=39)$, the time between tau PET acquisition and fMRI acquisition was over a year. In the subset of data collected within a single year $(n=48)$, we reexamined the relation between inferior temporal tau and hippocampal activity. In this subset, we found a stronger association between hippocampal hyperactivity and inferior temporal tau $(r=0.408$ $\mathrm{df}=46 ; t=3.03 ; p=0.004)$. Thus, the findings might underestimate the relationship between hippocampal hyperactivity and inferior temporal tau due to the delay between tau PET and fMRI acquisition. A third limitation is that task-evoked fMRI depends on the task and contrast (Gusnard and Raichle, 2001; Stark and Squire, 2001), as also discussed above in relation to (Marks et al., 2017). As a consequence, our findings, although consistent, are not directly comparable with studies that used different task paradigms.

\section{Implications}

We still lack an effective treatment for Alzheimer's disease (Selkoe, 2012). The association between hippocampal hyperactivity and tau accumulation in clinically normal older adults supports the idea that neuronal hyperactivity is a potential target for treatment in Alzheimer's disease (Bakker et al., 2012; Busche and Konnerth, 2015; Haberman et al., 2017b). Hyperactive neurons could be partially responsible for memory dysfunction and reducing hyperactivity may be beneficial for hippocampally mediated memory (Bakker et al., 2015). Second, in terms of prevention of AD, hyperactive neurons increase the release of excitotoxic amyloid and tau proteins in the synaptic cleft and could facilitate the spread of AD pathology throughout the brain (Cirrito et al., 2005; Yamada et al., 2014; Krüger and Mandelkow, 2016). AV1451 and other tau PET tracers, together with amyloid- $\beta$ PET, are likely to play a vital role in the characterization of preclinical Alzheimer's disease pathology. This will help further elucidate the role of aberrant activity in the hippocampus in the preclinical trajectory of Alzheimer's disease. To fully prevent cognitive decline, particularly in the later stages of preclinical $\mathrm{AD}$, we may need to pursue other mechanisms beyond amyloid or tau and consider therapies that mitigate excitotoxicity (Sperling et al., 2014b).

\section{References}

Abramowski D, Wiederhold KH, Furrer U, Jaton AL, Neuenschwander A, Runser MJ, Danner S, Reichwald J, Ammaturo D, Staab D, Stoeckli M, Rueeger H, Neumann U, Staufenbiel M (2008) Dynamics of Abeta turnover and deposition in different -amyloid precursor protein transgenic mouse models following -secretase inhibition. J Pharmacol Exp Ther 327: 411-424. CrossRef Medline

Bakker A, Krauss GL, Albert MS, Speck CL, Jones LR, Stark CE, Yassa MA, Bassett SS, Shelton AL, Gallagher M (2012) Reduction of hippocampal hyperactivity improves cognition in amnestic mild cognitive impairment. Neuron 74:467-474. CrossRef Medline

Bakker A, Albert MS, Krauss G, Speck CL, Gallagher M (2015) Response of the medial temporal lobe network in amnestic mild cognitive impairment to therapeutic intervention assessed by fMRI and memory task performance. Neuroimage 7:688-698. CrossRef Medline

Barulli D, Stern Y (2013) Efficiency, capacity, compensation, maintenance, plasticity: emerging concepts in cognitive reserve. Trends Cogn Sci 17: 502-509. CrossRef Medline
Becker JA, Hedden T, Carmasin J, Maye J, Rentz DM, Putcha D, Fischl B, Greve DN, Marshall GA, Salloway S, Marks D, Buckner RL, Sperling RA, Johnson KA (2011) Amyloid- $\beta$ associated cortical thinning in clinically normal elderly. Ann Neurol 69:1032-1042. CrossRef Medline

Bero AW, Yan P, Roh JH, Cirrito JR, Stewart FR, Raichle ME, Lee JM, Holtzman DM (2011) Neuronal activity regulates the regional vulnerability to amyloid- $\beta$ deposition. Nat Neurosci 14:750-756. CrossRef Medline

Bookheimer SY, Strojwas MH, Cohen MS, Saunders AM, Pericak-Vance MA, Mazziotta JC, Small GW (2000) Patterns of brain activation in people at risk for Alzheimer's disease. N Engl J Med 343:450-456. CrossRef Medline

Braak H, Braak E (1991) Neuropathological stageing of alzheimer-related changes. Acta Neuropathol 82:239-259. CrossRef Medline

Buckley RF, Schultz AP, Hedden T, Papp KV, Hanseeuw BJ, Marshall G, Sepulcre J, Smith EE, Rentz DM, Johnson KA, Sperling RA, Chhatwal JP (2017) Functional network integrity presages cognitive decline in preclinical Alzheimer disease. Neurology 89:29-37. CrossRef Medline

Buckner RL, Snyder AZ, Shannon BJ, LaRossa G, Sachs R, Fotenos AF, Sheline YI, Klunk WE, Mathis CA, Morris JC, Mintun MA (2005) Molecular, structural, and functional characterization of Alzheimer's disease: evidence for a relationship between default activity, amyloid, and memory. J Neurosci 25:7709-7717. CrossRef Medline

Busche MA, Konnerth A (2015) Neuronal hyperactivity-A key defect in Alzheimer's disease? BioEssays 37:624-632. CrossRef Medline

Busche MA, Eichhoff G, Adelsberger H, Abramowski D, Wiederhold KH, Haass C, Staufenbiel M, Konnerth A, Garaschuk O (2008) Clusters of hyperactive neurons near amyloid plaques in a mouse model of Alzheimer's disease. Science 321:1686-1689. CrossRef Medline

Cacucci F, Yi M, Wills TJ, Chapman P, O’Keefe J (2008) Place cell firing correlates with memory deficits and amyloid plaque burden in Tg2576 Alzheimer mouse model. Proc Natl Acad Sci U S A 105:7863-7868. CrossRef Medline

Cirrito JR, Yamada KA, Finn MB, Sloviter RS, Bales KR, May PC, Schoepp DD, Paul SM, Mennerick S, Holtzman DM (2005) Synaptic activity regulates interstitial fluid amyloid- $\beta$ levels in vivo. Neuron 48:913-922. CrossRef Medline

Dagley A, LaPoint M, Huijbers W, Hedden T, McLaren DG, Chatwal JP, Papp KV, Amariglio RE, Blacker D, Rentz DM, Johnson KA, Sperling RA, Schultz AP (2017) Harvard aging brain study: dataset and accessibility. Neuroimage 144:255-258. CrossRef Medline

Dale AM (1999) Optimal experimental design for event-related fMRI. Hum Brain Mapp 8:109-114. CrossRef Medline

Daselaar SM, Prince SE, Cabeza R (2004) When less means more: deactivations during encoding that predict subsequent memory. Neuroimage 23: 921-927. CrossRef Medline

Dennis NA, Browndyke JN, Stokes J, Need A, Burke JR, Welsh-Bohmer KA, Cabeza R (2010) Temporal lobe functional activity and connectivity in young adult. Alzheimers Dement 6:303-311. CrossRef Medline

DeVos SL, Goncharoff DK, Chen G, Kebodeaux CS, Yamada K, Stewart FR, Schuler DR, Maloney SE, Wozniak DF, Rigo F, Bennett CF, Cirrito JR, Holtzman DM, Miller TM (2013) Antisense reduction of tau in adult mice protects against seizures. J Neurosci 33:12887-12897. CrossRef Medline

Elman JA, Oh H, Madison CM, Baker SL, Vogel JW, Marks SM, Crowley S, O'Neil JP, Jagust WJ (2014) Neural compensation in older people with brain amyloid- $\beta$ deposition. Nat Neurosci 17:1316-1318. CrossRef Medline

Filippini N, Ebmeier KP, MacIntosh BJ, Trachtenberg AJ, Frisoni GB, Wilcock GK, Beckmann CF, Smith SM, Matthews PM, Mackay CE (2011) Differential effects of the APOE genotype on brain function across the lifespan. Neuroimage 54:602-610. CrossRef Medline

Folstein MF, Folstein SE, McHugh PR (1975) “Mini-mental state": A practical method for grading the cognitive state of patients for the clinician. J Psychiatr Res 12:189-198. CrossRef Medline

Foster CM, Kennedy KM, Horn MM, Hoagey DA, Rodrigue KM (2018) Both hyper- and hypo-activation to cognitive challenge are associated with increased beta-amyloid deposition in healthy aging: a nonlinear effect. Neuroimage 166:285-292. CrossRef Medline

Fox J, Weisberg S (2011) An R companion to applied regression. Thousand Oaks: California Sage.

Fox MD, Snyder AZ, Vincent JL, Corbetta M, Van Essen DC, Raichle ME (2005) The human brain is intrinsically organized into dynamic, anticor- 
related functional networks. Proc Natl Acad Sci U S A 102:9673-9678. CrossRef Medline

Franzmeier N, Buerger K, Teipel S, Stern Y, Dichgans M, Ewers M; Alzheimer's Disease Neuroimaging Initiative (ADNI) (2017) Cognitive reserve moderates the association between functional network anticorrelations and memory in MCI. Neurobiol Aging 50:152-162. CrossRef Medline

Franzmeier N, Düzel E, Jessen F, Buerger K, Levin J, Duering M, Dichgans M, Haass C, Suárez-Calvet M, Fagan AM, Paumier K, Benzinger T, Masters CL, Morris JC, Perneczky R, Janowitz D, Catak C, Wolfsgruber S, Wagner M, Teipel S, et al. (2018) Left frontal hub connectivity delays cognitive impairment in autosomal-dominant and sporadic Alzheimer's disease. Brain 141:1186-1200. CrossRef Medline

Gilmore AW, Nelson SM, McDermott KB (2015) A parietal memory network revealed by multiple MRI methods. Trends Cogn Sci 19:534-543. CrossRef Medline

Goodale MA, Milner AD (1992) Separate visual pathways for perception and action. Trends Neurosci 15:20-25. CrossRef Medline

Greve DN, Salat DH, Bowen SL, Izquierdo-Garcia D, Schultz AP, Catana C, Becker JA, Svarer C, Knudsen GM, Sperling RA, Johnson KA (2016) Different partial volume correction methods lead to different conclusions: an ${ }^{18}$ F-FDG-PET study of aging. Neuroimage 132:334-343. CrossRef Medline

Gusnard DA, Raichle ME (2001) Searching for a baseline: functional imaging and the resting human brain. Nat Rev Neurosci 2:685-694. CrossRef Medline

Haberman RP, Branch A, Gallagher M (2017a) Targeting neural hyperactivity as a treatment to stem progression of late-onset Alzheimer's disease. Neurotherapeutics 14:662-676. CrossRef Medline

Haberman RP, Koh MT, Gallagher M (2017b) Heightened cortical excitability in aged rodents with memory impairment. Neurobiol Aging 54: 144-151. CrossRef Medline

Hämäläinen A, Pihlajamäki M, Tanila H, Hänninen T, Niskanen E, Tervo S, Karjalainen PA, Vanninen RL, Soininen H (2007) Increased fMRI responses during encoding in mild cognitive impairment. Neurobiol Aging 28:1889-1903. CrossRef Medline

Huijbers W, Mormino EC, Wigman SE, Ward AM, Vannini P, McLaren DG, Becker JA, Schultz AP, Hedden T, Johnson KA, Sperling RA (2014) Amyloid deposition is linked to aberrant entorhinal activity among cognitively normal older adults. J Neurosci 34:5200-5210. CrossRef Medline

Huijbers W, Mormino EC, Schultz AP, Wigman S, Ward AM, Larvie M, Amariglio RE, Marshall GA, Rentz DM, Johnson KA, Sperling RA (2015) Amyloid- $\beta$ deposition in mild cognitive impairment is associated with increased hippocampal activity, atrophy and clinical progression. Brain 138:1023-1035. CrossRef Medline

Huijbers W, Papp KV, LaPoint M, Wigman SE, Dagley A, Hedden T, Rentz DM, Schultz AP, Sperling RA (2017) Age-related increases in tip-of-thetongue are distinct from decreases in remembering names: a functional MRI study. Cereb Cortex 27:4339-4349. CrossRef Medline

Jack CR Jr, Bennett DA, Blennow K, Carrillo MC, Feldman HH, Frisoni GB, Hampel H, Jagust WJ, Johnson KA, Knopman DS, Petersen RC, Scheltens P, Sperling RA, Dubois B (2016) A/T/N: an unbiased descriptive classification scheme for Alzheimer disease biomarkers. Neurology 87:539547. CrossRef Medline

Jack CR Jr, Wiste HJ, Schwarz CG, Lowe VJ, Senjem ML, Vemuri P, Weigand SD, Therneau TM, Knopman DS, Gunter JL, Jones DT, Graff-Radford J, Kantarci K, Roberts RO, Mielke MM, Machulda MM, Petersen RC (2018) Longitudinal tau PET in ageing and Alzheimer's disease. Brain 141:1517-1528. CrossRef Medline

Jagust WJ (2016) Early life sets the stage for aging. Proc Natl Acad Sci U S A 113:9148-9150. CrossRef Medline

Johnson KA, Gregas M, Becker JA, Kinnecom C, Salat DH, Moran EK, Smith EE, Rosand J, Rentz DM, Klunk WE, Mathis CA, Price JC, Dekosky ST, Fischman AJ, Greenberg SM (2007) Imaging of amyloid burden and distribution in cerebral amyloid angiopathy. Ann Neurol 62:229-234. CrossRef Medline

Johnson KA, Schultz A, Betensky RA, Becker JA, Sepulcre J, Rentz D, Mormino E, Chhatwal J, Amariglio R, Papp K, Marshall G, Albers M, Mauro S, Pepin L, Alverio J, Judge K, Philiossaint M, Shoup T, Yokell D, Dickerson $\mathrm{B}$, et al. (2016) Tau positron emission tomographic imaging in aging and early alzheimer disease. Ann Neurol 79:110-119. CrossRef Medline

Johnson SC, Schmitz TW, Trivedi MA, Ries ML, Torgerson BM, Carlsson CM, Asthana S, Hermann BP, Sager MA (2006) The influence of alzhei- mer disease family history and apolipoprotein $\mathrm{E} \epsilon 4$ on mesial temporal lobe activation. J Neurosci 26:6069-6076. CrossRef Medline

Johnson SC, Baxter LC, Susskind-Wilder L, Connor DJ, Sabbagh MN, Caselli RJ (2004) Hippocampal adaptation to face repetition in healthy elderly and mild cognitive impairment. Neuropsychologia 42:980-989. CrossRef Medline

Kennedy KM, Rodrigue KM, Devous MD Sr, Hebrank AC, Bischof GN, Park DC (2012) Effects of beta-amyloid accumulation on neural function during encoding across the adult lifespan. Neuroimage 62:1-8. CrossRef Medline

Kircher TT, Weis S, Freymann K, Erb M, Jessen F, Grodd W, Heun R, Leube DT (2007) Hippocampal activation in patients with mild cognitive impairment is necessary for successful memory encoding. J Neurol Neurosurg Psychiatry 78:812-818. CrossRef Medline

Klunk WE, Engler H, Nordberg A, Wang Y, Blomqvist G, Holt DP, Bergström M, Savitcheva I, Huang GF, Estrada S, Ausén B, Debnath ML, Barletta J, Price JC, Sandell J, Lopresti BJ, Wall A, Koivisto P, Antoni G, Mathis CA, et al. (2004) Imaging brain amyloid in Alzheimer's disease with Pittsburgh compound-B. Ann Neurol 55:306-319. CrossRef Medline

Krüger L, Mandelkow EM (2016) Tau neurotoxicity and rescue in animal models of human tauopathies. Curr Opin Neurobiol 36:52-58. CrossRef Medline

Leal SL, Landau SM, Bell RK, Jagust WJ (2017) Hippocampal activation is associated with longitudinal amyloid accumulation and cognitive decline. eLife 6:e22978. CrossRef Medline

Lockhart SN, Schöll M, Baker SL, Ayakta N, Swinnerton KN, Bell RK, Mellinger TJ, Shah VD, O’Neil JP, Janabi M, Jagust WJ (2017) Amyloid and tau PET demonstrate region-specific associations in normal older people. Neuroimage 150:191-199. CrossRef Medline

Logan J, Fowler JS, Volkow ND, Wolf AP, Dewey SL, Schlyer DJ, MacGregor RR, Hitzemann R, Bendriem B, Gatley SJ (1990) Graphical analysis of reversible radioligand binding from time-activity measurements applied to $\left[N-{ }^{11} \mathrm{C}\right.$-methyl] $-(-)$-cocaine PET studies in human subjects. J Cereb Blood Flow Metab 10:740-747. CrossRef Medline

Marks SM, Lockhart SN, Baker SL, Jagust WJ (2017) Tau and $\beta$-amyloid are associated with medial temporal lobe structure, function, and memory encoding in normal aging. J Neurosci 37:3192-3201. CrossRef Medline

Mathis CA, Bacskai BJ, Kajdasz ST, McLellan ME, Frosch MP, Hyman BT, Holt DP, Wang Y, Huang GF, Debnath ML, Klunk WE (2002) A lipophilic thioflavin-T derivative for positron emission tomography (PET) imaging of amyloid in brain. Bioorg Med Chem Lett 12:295-298. CrossRef Medline

Miller SL, Celone K, DePeau K, Diamond E, Dickerson BC, Rentz D, Pihlajamäki M, Sperling RA (2008) Age-related memory impairment associated with loss of parietal deactivation but preserved hippocampal activation. Proc Natl Acad Sci U S A 105:2181-2186. CrossRef Medline

Mormino EC, Kluth JT, Madison CM, Rabinovici GD, Baker SL, Miller BL, Koeppe RA, Mathis CA, Weiner MW, Jagust WJ; Alzheimer's Disease Neuroimaging Initiative (2009) Episodic memory loss is related to hippocampal-mediated -amyloid deposition in elderly subjects. Brain 132:1310-1323. CrossRef Medline

Mormino EC, Brandel MG, Madison CM, Marks S, Baker SL, Jagust WJ (2012) A $\beta$ deposition in aging is associated with increases in brain activation during successful memory encoding. Cereb Cortex 22:1813-1823. CrossRef Medline

Mormino EC, Betensky RA, Hedden T, Schultz AP, Ward A, Huijbers W, Rentz DM, Johnson KA, Sperling RA; Alzheimer's Disease Neuroimaging Initiative, Australian Imaging Biomarkers and Lifestyle Flagship Study of Ageing, Harvard Aging Brain Study (2014) Amyloid and APOE $\varepsilon 4$ interact to influence short-term decline in preclinical alzheimer disease. Neurology 82:1760-1767. CrossRef Medline

Morris JC (1993) The clinical dementia rating (CDR): current version and scoring rules. Neurology 43:2412-2414. Medline

Nelson PT, Alafuzoff I, Bigio EH, Bouras C, Braak H, Cairns NJ, Castellani RJ, Crain BJ, Davies P, Del Tredici K, Duyckaerts C, Frosch MP, Haroutunian V, Hof PR, Hulette CM, Hyman BT, Iwatsubo T, Jellinger KA, Jicha GA, Kövari E, et al. (2012) Correlation of Alzheimer disease neuropathologic changes with cognitive status. J Neuropathol Exp Neurol 71:362-381. CrossRef Medline

Oh H, Jagust WJ (2013) Frontotemporal network connectivity during memory encoding is increased with aging and disrupted by beta-amyloid. J Neurosci 33:18425-18437. CrossRef Medline 
Ossenkoppele R, Schonhaut DR, Schöll M, Lockhart SN, Ayakta N, Baker SL, O’Neil JP, Janabi M, Lazaris A, Cantwell A, Vogel J, Santos M, Miller ZA, Bettcher BM, Vossel KA, Kramer JH, Gorno-Tempini ML, Miller BL, Jagust WJ, Rabinovici GD (2016) Tau PET patterns mirror clinical and neuroanatomical variability in Alzheimer's disease. Brain 139:1551-1567. CrossRef Medline

Palop JJ, Mucke L (2010) Amyloid-beta-induced neuronal dysfunction in Alzheimer's disease: from synapses toward neural networks. Nat Neurosci 13:812-818. CrossRef Medline

Palop JJ, Mucke L (2016) Network abnormalities and interneuron dysfunction in Alzheimer disease. Nat Rev Neurosci 17:777-792. CrossRef Medline

Palop JJ, Chin J, Roberson ED, Wang J, Thwin MT, Bien-Ly N, Yoo J, Ho KO, Yu GQ, Kreitzer A, Finkbeiner S, Noebels JL, Mucke L (2007) Aberrant excitatory neuronal activity and compensatory remodeling of inhibitory hippocampal circuits in mouse models of Alzheimer's disease. Neuron 55:697-711. CrossRef Medline

Park DC, Reuter-Lorenz P (2009) The adaptive brain: aging and neurocognitive scaffolding. Annu Rev Psychol 60:173-196. CrossRef Medline

Petersen RC (2004) Mild cognitive impairment as a diagnostic entity. J Intern Med 256:183-194. CrossRef Medline

Quiroz YT, Budson AE, Celone K, Ruiz A, Newmark R, Castrillón G, Lopera F, Stern CE (2010) Hippocampal hyperactivation in presymptomatic familial Alzheimer's disease. Ann Neurol 68:865-875. CrossRef Medline

Quiroz YT, Schultz AP, Chen K, Protas HD, Brickhouse M, Fleisher AS, Langbaum JB, Thiyyagura P, Fagan AM, Shah AR, Muniz M, ArboledaVelasquez JF, Munoz C, Garcia G, Acosta-Baena N, Giraldo M, Tirado V, Ramírez DL, Tariot PN, Dickerson BC et al. (2015) Brain imaging and blood biomarker abnormalities in children with autosomal dominant Alzheimer disease: a cross-sectional study. JAMA Neurol 72:912-919. CrossRef Medline

Raichle ME, MacLeod AM, Snyder AZ, Powers WJ, Gusnard DA, Shulman GL (2001) A default mode of brain function. Proc Natl Acad Sci U S A 98:676-682. CrossRef Medline

Rao SC, Dove G, Cascino GD, Petersen RC (2009) Recurrent seizures in patients with dementia: frequency, seizure types, and treatment outcome. Epilepsy Behav 14:118-120. CrossRef Medline

Reiman EM, Quiroz YT, Fleisher AS, Chen K, Velez-Pardo C, Jimenez-DelRio M, Fagan AM, Shah AR, Alvarez S, Arbelaez A, Giraldo M, AcostaBaena N, Sperling RA, Dickerson B, Stern CE, Tirado V, Munoz C, Reiman RA, Huentelman MJ, Alexander GE, et al. (2012) Brain imaging and fluid biomarker analysis in young adults at genetic risk for autosomal dominant Alzheimer's disease in the presenilin 1 E280A kindred: a casecontrol study. Lancet Neurol 11:1048-1056. CrossRef Medline

Rieck JR, Rodrigue KM, Kennedy KM, Devous MD Sr, Park DC (2015) The effect of beta-amyloid on face processing in young and old adults: a multivariate analysis of the BOLD signal. Hum Brain Mapp 36:2514-2526. CrossRef Medline

Rousset OG, Ma Y, Evans AC (1998) Correction for partial volume effects in PET: principle and validation. J Nucl Med 39:904-911. Medline

Rugg MD, Vilberg KL (2013) Brain networks underlying episodic memory retrieval. Curr Opin Neurobiol 23:255-260. CrossRef Medline

Schöll M, Lockhart SN, Schonhaut DR, O’Neil JP, Janabi M, Ossenkoppele R, Baker SL, Vogel JW, Faria J, Schwimmer HD, Rabinovici GD, Jagust WJ (2016) PET imaging of tau deposition in the aging human brain. Neuron 89:971-982. CrossRef Medline

Selkoe DJ (2012) Preventing Alzheimer's disease. Science 337:1488-1492. CrossRef Medline

Sperling RA, LaViolette PS, O’Keefe K, O’Brien J, Rentz DM, Pihlajamaki M, Marshall G, Hyman BT, Selkoe DJ, Hedden T, Buckner RL, Becker JA,
Johnson KA (2009) Amyloid deposition is associated with impaired default network function in older persons without dementia. Neuron 63 : 178-188. CrossRef Medline

Sperling R, Mormino E, Johnson K (2014a) The evolution of preclinical Alzheimer's disease: implications for prevention trials. Neuron 84:608622. CrossRef Medline

Sperling RA, Rentz DM, Johnson KA, Karlawish J, Donohue M, Salmon DP, Aisen P (2014b) The A4 study: stopping AD before symptoms begin? Sci Transl Med 6:228fs13. CrossRef Medline

Stark CE, Squire LR (2001) When zero is not zero: the problem of ambiguous baseline conditions in fMRI. Proc Natl Acad Sci U S A 98:1276012766. CrossRef Medline

Stern Y, Habeck C, Moeller J, Scarmeas N, Anderson KE, Hilton HJ, Flynn J, Sackeim H, van Heertum R (2005) Brain networks associated with cognitive reserve in healthy young and old adults. Cereb Cortex 15:394-402. CrossRef Medline

Tran TT, Speck CL, Pisupati A, Gallagher M, Bakker A (2017) Increased hippocampal activation in ApoE-4 carriers and non-carriers with amnestic mild cognitive impairment. Neuroimage Clin 13:237-245. CrossRef Medline

Vannini P, Hedden T, Huijbers W, Ward A, Johnson KA, Sperling RA (2013) The ups and downs of the posteromedial cortex: age- and amyloid-related functional alterations of the encoding/retrieval flip in cognitively normal older adults. Cereb Cortex 23:1317-1328. CrossRef Medline

Villemagne VL, Chételat G (2016) Neuroimaging biomarkers in Alzheimer's disease and other dementias. Ageing Res Rev 30:4-16. CrossRef Medline

Vossel KA, Beagle AJ, Rabinovici GD, Shu H, Lee SE, Naasan G, Hegde M, Cornes SB, Henry ML, Nelson AB, Seeley WW, Geschwind MD, Shih T, Kirsch HE, Garcia PA, Miller BL, Mucke L (2013) Seizures and epileptiform activity in the early stages of Alzheimer disease. JAMA Neurol 70:1158-1166. CrossRef Medline

Vossel KA, Ranasinghe KG, Beagle AJ, Mizuiri D, Honma SM, Dowling AF, Darwish SM, Van Berlo V, Barnes DE, Mantle M, Karydas AM, Coppola G, Roberson ED, Miller BL, Garcia PA, Kirsch HE, Mucke L, Nagarajan SS (2016) Incidence and impact of subclinical epileptiform activity in Alzheimer's disease. Ann Neurol 80:858-870. CrossRef Medline

Wechsler D (1984) Wechsler memory scale-revised: manual. San Antonio, TX: Psychological.

Wu JW, Hussaini SA, Bastille IM, Rodriguez GA, Mrejeru A, Rilett K, Sanders DW, Cook C, Fu H, Boonen RA, Herman M, Nahmani E, Emrani S, Figueroa YH, Diamond MI, Clelland CL, Wray S, Duff KE (2016) Neuronal activity enhances tau propagation and tau pathology in vivo. Nat Neurosci 19:1085-1092. CrossRef Medline

Xia CF, Arteaga J, Chen G, Gangadharmath U, Gomez LF, Kasi D, Lam C, Liang Q, Liu C, Mocharla VP, Mu F, Sinha A, Su H, Szardenings AK, Walsh JC, Wang E, Yu C, Zhang W, Zhao T, Kolb HC (2013) $\left[{ }^{18} \mathrm{~F}\right] \mathrm{T} 807$, a novel tau positron emission tomography imaging agent for Alzheimer's disease. Alzheimers Dement 9:666-676. CrossRef Medline

Yamada K, Holth JK, Liao F, Stewart FR, Mahan TE, Jiang H, Cirrito JR, Patel TK, Hochgräfe K, Mandelkow EM, Holtzman DM (2014) Neuronal activity regulates extracellular tau in vivo. J Exp Med 211:387-393. CrossRef Medline

Yassa MA, Stark CE (2011) Pattern separation in the hippocampus. Trends Neurosci 34:515-525. CrossRef Medline

Zarea A, Charbonnier C, Rovelet-Lecrux A, Nicolas G, Rousseau S, Borden A, Pariente J, Le Ber I, Pasquier F, Formaglio M, Martinaud O, Rollin-Sillaire A, Sarazin M, Croisile B, Boutoleau-Bretonnière C, Ceccaldi M, Gabelle A, Chamard L, Blanc F, Sellal F, et al. (2016) Seizures in dominantly inherited Alzheimer disease. Neurology 87:912-919. CrossRef Medline 